\title{
Nitrides as ammonia synthesis catalysts and as potential nitrogen transfer reagents
}

\author{
J. S. J. Hargreaves
}

Received: 5 February 2014/ Accepted: 27 February 2014/Published online: 19 March 2014

(C) The Author(s) 2014. This article is published with open access at Springerlink.com

\begin{abstract}
In this article, an overview of the application of selected metal nitrides as ammonia synthesis catalysts is presented. The potential development of some systems into nitrogen transfer reagents is also described.
\end{abstract}

Keywords Nitrogen - Hydrogen - Catalysis · Ammonia . Nitrides

\section{Introduction}

The successful development of the Haber-Bosch Process for the production of ammonia was a paramount achievement of the twentieth Century. Through the provision of an accessible route to synthetic fertiliser, it has been pivotal in sustaining a large proportion of the global population [1]. The process involves the direct combination of pure $\mathrm{H}_{2}$ and $\mathrm{N}_{2}$ reactants over promoted iron catalyst at moderate temperature (typically ca $400{ }^{\circ} \mathrm{C}$ ) and high pressure (typically 100-200 atmospheres):

$0.5 \mathrm{~N}_{2(\mathrm{~g})}+1.5 \mathrm{H}_{2(\mathrm{~g})} \leftrightarrow \mathrm{NH}_{3(\mathrm{~g})} \Delta \mathrm{H}^{\circ}=-46 \mathrm{~kJ} \mathrm{~mol}^{-1}$

The reaction is equilibrium limited and, being exothermic, is thermodynamically favoured at lower reaction temperatures. However, the temperature of operation is dictated by the requirement to achieve acceptable process kinetics. Whilst the Haber-Bosch Process can, to some extent, be viewed as a mature technology, the development of more active (or even more poison tolerant) catalysts which would allow a reduction in the stringent conditions of

J. S. J. Hargreaves $(\bowtie)$

WestCHEM, School of Chemistry, University of Glasgow,

Joseph Black Building, Glasgow G12 8QQ, UK

e-mail: Justin.Hargreaves@glasgow.ac.uk operation is of significant interest. In this context, it is salient to note that, taken in its entirety, including the provision and purification of reactant feedstreams, on a global scale, the operation of the Haber Process currently consumes 1-2 \% of the world's energy demand, e.g. [2, 3]. Therefore, any improvements can potentially yield massive rewards both in terms of economic and environmental benefits. The identification and application of more active catalysts could lead to lowering of the process temperatures and/or pressures of operation necessary to achieve a desired space time yield of product. Indeed, lowered reaction temperatures result in improved obtainable equilibrium yields offering the tantalising prospect of a possible win-win situation, providing sufficiently favourable kinetics can be achieved. This is, however, a very significant challenge.

Iron is cheap and abundant and, when promoted, very effective under current Haber-Bosch Process conditions. Therefore, any replacement catalyst must afford the opportunity of significantly higher activity leading to lower temperature and/or pressure of application. Indeed, a number alternative systems based upon ruthenium have been identified in the literature, e.g. [4-7]. One such system involving promoted ruthenium supported on carbon is 10-20 times more active than conventional iron systems while operating at lower reaction pressure and forms the basis of an alternative ammonia synthesis process, the Kellogg Advanced Ammonia Process [8, 9].

The focus of this overview is a description of some of the relatively recent literature relating to the activity of metal nitrides as ammonia synthesis catalysts. The potential of nitrides as possible nitrogen transfer reagents will also be considered. In some respects, this relates to historical work on the development of the Haber-Bosch Process where some early studies by Mittasch and coworkers [10] at BASF considered routes to nitrogen 
fixation involving the formation of nitrides and also demonstrated some nitrides, such as molybdenum nitride, to be intermediates in the stepwise synthesis of ammonia via nitridation of metals with $\mathrm{N}_{2}$ and subsequent reduction by $\mathrm{H}_{2}$.

\section{Metal nitrides as ammonia synthesis catalysts}

Binary metal nitrides

In the early studies, Mittasch [10] drew attention to molybdenum metal which was stated to catalyse ammonia synthesis differently from iron in that it formed easily detectable amounts of nitride during catalysis. It was said to resemble tungsten, manganese and uranium in this respect. It is therefore to be expected that nitrides of such metals may be active ammonia synthesis catalysts. However, mention should also be made that under industrial conditions bulk iron nitridation occurs resulting in the distorted structure associated with catalytic activity [11].

A number of binary nitrides have been identified as active ammonia synthesis catalysts in the literature, including those of molybdenum [10, 12-14], uranium $[15,16]$, vanadium $[17,18]$, rhenium $[19,20]$ and cerium [21].

In the case of molybdenum, arguably the most wellstudied binary nitride, structure sensitivity has been reported to be operative over $\gamma-\mathrm{Mo}_{2} \mathrm{~N}$ in studies involving systematic variation of particle size [12]. In these studies, it was proposed that the fraction of active sites decreased with decreasing particle size. However, the effect of morphology was found to be limited in a study comparing plate like $\gamma-\mathrm{Mo}_{2} \mathrm{~N}$ and nanorod form of $\gamma-\mathrm{Mo}_{2} \mathrm{~N}$ prepared by the temperature programmed ammonolysis of plate and nanorod $\mathrm{MoO}_{3}$, respectively [14]. Such ammonolysis is known to yield $\gamma-\mathrm{Mo}_{2} \mathrm{~N}$ which is pseudomorphic with respect to the $\mathrm{MoO}_{3}$ precursor [22]. Comparison of different phases of molybdenum nitride showed $\beta-\mathrm{Mo}_{2} \mathrm{~N}_{0.78}$ to possess similar activity to its $\gamma-\mathrm{Mo}_{2} \mathrm{~N}$ counterpart, whereas $\delta$-MoN was found to be inactive (although potential deleterious effects resulting from residual sulphur left over from the preparation of this phase by ammonolysis of $\mathrm{MoS}_{2}$ could not be excluded) [14]. The $\beta$ nitride phase can be prepared by reaction of $\mathrm{MoO}_{3}$ with $\mathrm{N}_{2} / \mathrm{H}_{2}$ mixtures [23] and the $\delta$ phase by ammonolysis of either $\mathrm{MoS}_{2}$ or $\mathrm{MoCl}_{5}$ [24]. Applying ${ }^{15} \mathrm{~N}$ labelling to study the mechanism of ammonia synthesis over molybdenum nitride, Aika and Ozaki [25] deduced rate determining $\mathrm{N}_{2}$ activation leading to intermediate $\mathrm{N}_{(\mathrm{a})}$. It was argued that a proportion of the ${ }^{15} \mathrm{~N}$ was lost into bulk nitride, with the following scheme being presented:

$$
\begin{aligned}
& \mathrm{N}_{2} \rightarrow \mathrm{N}_{(\mathrm{a})} \leftrightarrow \mathrm{NH}_{3} \\
& \uparrow \\
& \mathrm{Mo}_{2} \mathrm{~N}
\end{aligned}
$$

and similarities with iron nitride, previously investigated by Logan et al. [26], were drawn. Contrary to this, Hillis et al. [27] had reported the hydrogenation of $\mathrm{NH}_{x}$ species to be rate determining and the rate of hydrogenation of bulk nitride to be around 20-50 times slower than ammonia synthesis in this system. Some studies have been undertaken on other binary nitride systems. For example, based upon unusual transient behaviour, the hydrogenation of bulk nitrogen in uranium nitride has been proposed with the suggestion being made of a possible dynamic process between nitrogen species not immediately hydrogenated and loosely bonded subsurface nitrogen species which subsequently diffuse to the surface where they are hydrogenated to form ammonia [15]. This is akin to some oxidation processes which occur by the Mars-van Krevelen process where lattice oxygen species are those active in catalytic oxidation reactions [28]. Phase stability may be a consideration in other systems, for example, in rhenium nitride, the active form of the catalyst is proposed to comprise a mixture of $\operatorname{Re}_{3} \mathrm{~N}$ and $\operatorname{Re}[19]$.

Ternary metal nitrides

In recent years, there have been reports that $\mathrm{Co}_{3} \mathrm{Mo}_{3} \mathrm{~N}$ related catalysts have high activity that have attracted interest [29-35]. In particular, it has been reported that when suitably promoted, the activity of this phase can exceed that of conventional iron based Haber-Bosch catalysts. Table 1 presents some activity data taken from a study by Aika and Kojima [29]. $\mathrm{Cs}^{+}$has been found to be a promoter up to a certain limit, beyond which phase decomposition occurs [29]. Preparation of the phase generally involves ammonolysis of hydrated cobalt molybdate precursor-perhaps surprisingly use of anhydrous cobalt

Table 1 Ammonia synthesis activities of various catalysts (adapted from [29])

\begin{tabular}{llll}
\hline Catalyst & $\begin{array}{l}\text { Rate } \\
\left(\mu \mathrm{mol} \mathrm{h}{ }^{-1} \mathrm{~g}^{-1}\right)\end{array}$ & $\begin{array}{l}\text { Surface area } \\
\left(\mathrm{m}^{2} \mathrm{~g}^{-1}\right)\end{array}$ & $\begin{array}{l}\text { Specific activity } \\
\left(\mu \mathrm{mol} \mathrm{h}^{-1} \mathrm{~m}^{-2}\right)\end{array}$ \\
\hline $\mathrm{Fe}_{-} \mathrm{K}_{2} \mathrm{O}-\mathrm{Al}_{2} \mathrm{O}_{3}$ & 330 & 14 & 24 \\
$\mathrm{Co}_{3} \mathrm{Mo}_{3} \mathrm{~N}$ & 652 & 21 & 31 \\
$\mathrm{Co}_{3} \mathrm{Mo}_{3} \mathrm{~N}-\mathrm{K} 5$ & 869 & 17 & 51 \\
$\mathrm{Co}_{3} \mathrm{Mo}_{3} \mathrm{~N}-\mathrm{K} 30$ & 364 & 8 & 46 \\
$\mathrm{Co}_{3} \mathrm{Mo}_{3} \mathrm{~N}-\mathrm{Cs} 2$ & 986 & 16 & 62 \\
$\mathrm{Co}_{3} \mathrm{Mo}_{3} \mathrm{~N}-\mathrm{Cs} 10$ & 586 & 10 & 59 \\
\hline
\end{tabular}

Reaction conditions $400{ }^{\circ} \mathrm{C}$ and $0.1 \mathrm{MPa}$ 
molybdate is less effective. Ammonolysis may present a problem in large-scale application since, for example, heat transfer may be an issue as outlined in the case of the binary molybdenum nitride system [36, 37]. However, straight application of the hydrated molybdate precursor followed by in situ nitriding with $3 / 1 \mathrm{H}_{2} / \mathrm{N}_{2}$ at $700{ }^{\circ} \mathrm{C}$ for $2 \mathrm{~h}$ produced a less active catalyst which, although containing some $\mathrm{Co}_{3} \mathrm{Mo}_{3} \mathrm{~N}$, comprised additional phases [38].

The activity of the $\mathrm{Co}_{3} \mathrm{Mo}_{3} \mathrm{~N}$ phase has been rationalised in terms of the $\mathrm{N}_{2}$ binding energy by Norskov and coworkers [32] as shown in Fig. 1 which presents a comparison of the calculated turnover frequency for a range of materials as a function of $\mathrm{N}_{2}$ binding energy. The significance of $\mathrm{N}_{2}$ binding energy as an important parameter for a reaction process in which $\mathrm{N}_{2}$ dissociation is generally considered rate limiting has been discussed and justified [39]. In terms of the plot presented in Fig. 1, the high activity of $\mathrm{Ru}$ and $\mathrm{Fe}$, the basis for the two major industrial processes, as discussed in the introduction, can be seen. Osmium can also be seen to be a highly active catalyst-a fact recognised in the early work as outlined by Mittasch [10] in which uranium was also highlighted as having high activity. The high activity of $\mathrm{Fe}, \mathrm{Ru}$ and $\mathrm{Os}$ for ammonia synthesis represents an interesting group trend within the $\mathrm{d}$ block of the periodic table, although it is seldom, if ever, highlighted as so. In addition, the initial discovery of the activity of Os represents an early example of a currently popular aspect for consideration-scarcity of elements. At that stage, the global reserves of Os were only $100 \mathrm{~kg}$ and Os was also susceptible to oxidation to yield $\mathrm{OsO}_{4}$ and so its replacement in the process was of paramount importance, which led to the discovery of the promoted Fe system. In Norskov's work, the high activity of the $\mathrm{Co}_{3} \mathrm{Mo}_{3} \mathrm{~N}$ phase has been explained as an average of the $\mathrm{N}_{2}$ binding energies for Co (which is too weakly binding) and Mo (which is too strongly binding) arriving at an optimum in the Sabatier curve shown in Fig. 1, with the $\mathrm{Co}_{3} \mathrm{Mo}_{3} \mathrm{~N}$ catalyst reportedly being developed along this principle. It was argued that both components have to be in close proximity in order to be effective and that the (111) surface plane exhibits mixed Co and Mo sites. $\mathrm{N}$ was stated to not participate in the reaction but rather induce the required ordering. Support for this rationalisation was provided in previous microkinetic studies by the authors for which the activation energy was found to be intermediate between Co and Mo [32]. The volcano curve can also be used to rationalise the relatively high ammonia synthesis activity of the $\mathrm{Ni}_{2} \mathrm{Mo}_{3} \mathrm{~N}$ phase $[29,33] . \mathrm{Fe}_{3} \mathrm{Mo}_{3} \mathrm{~N}$, which is isostructural with $\mathrm{Co}_{3} \mathrm{Mo}_{3} \mathrm{~N}$, is also a high activity ternary nitride for the reaction [29, 33]. A perhaps somewhat related approach to the Sabatier curve are the experimental surface science studies by Attard and King [40] aimed towards the production of hybrid materials combining a

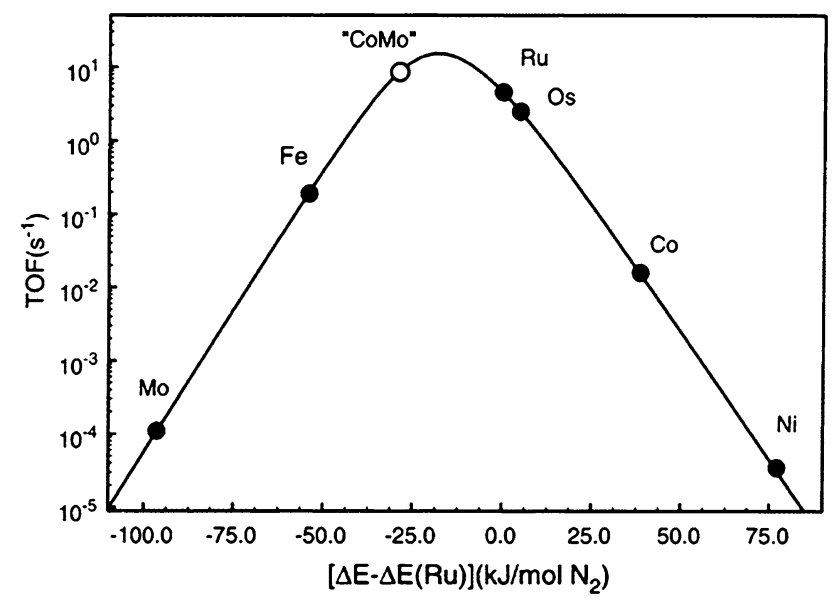

Fig. 1 Calculated turnover frequencies for ammonia synthesis as a function of the adsorption energy of nitrogen. The synthesis conditions are $400{ }^{\circ} \mathrm{C}, 50$ bar, gas composition $\mathrm{H}_{2} / \mathrm{N}_{2} 3 / 1$ containing $5 \% \mathrm{NH}_{3}$. Reproduced with permission from [32]. Copyright (2001) American Chemical Society

component with a marked ability to dissociate $\mathrm{N}_{2}$ with a high sticking probability with a component which bonds weakly to nitrogen in order to produce a nitrogen-metal bond of similar strength to Fe-N. The former component was $\mathrm{W}$, whilst $\mathrm{Cu}, \mathrm{Ag}$ and $\mathrm{Au}$ were examples of the latter component. It was found that $\mathrm{N}_{2}$ would not adsorb at sites consisting of both $\mathrm{W}$ and $\mathrm{Cu}$ atoms and hence it was predicted that bimetallics of W with Group IB metals would act as poor ammonia synthesis catalysts. However, if $\mathrm{N}_{2}$ could be dissociated by another route, the possibility of copper-tungsten bimetallics functioning as effective ammonia synthesis catalysts was raised.

In the context of high ammonia synthesis activity, it is interesting to draw attention to the reported high activity of cobalt-rhenium phases [19, 41]. Whilst these do not seem to have achieved the prominence of the $\mathrm{Co}_{3} \mathrm{Mo}_{3} \mathrm{~N}$ related systems, literature studies have indicated that the activity exceeds that of them. A $\mathrm{Co} / \mathrm{Re}$ material ratio of $1 / 4$ prepared by ammonolysis at $700{ }^{\circ} \mathrm{C}$ was found to be particularly effective and it was proposed that catalytic activity may relate to the presence of some form of rhenium nitride phase. However, the scarcity of rhenium and its relative cost may be a consideration in large-scale application, although it should be acknowledged that Pt-Re reforming catalysts are applied on an industrial scale and also that Co-Re catalysts for Fischer-Tropsch synthesis have been a focus of interest, e.g. [42]. Whilst many formulations were screened by Mittasch and colleagues [10] in the early development of ammonia synthesis catalysts, it is an interesting thought to note that rhenium as such would not have formed part of the matrix, since its discovery was not documented until 1925. Indeed, in these studies Co was even documented as a promoter of Mo which is fascinating 


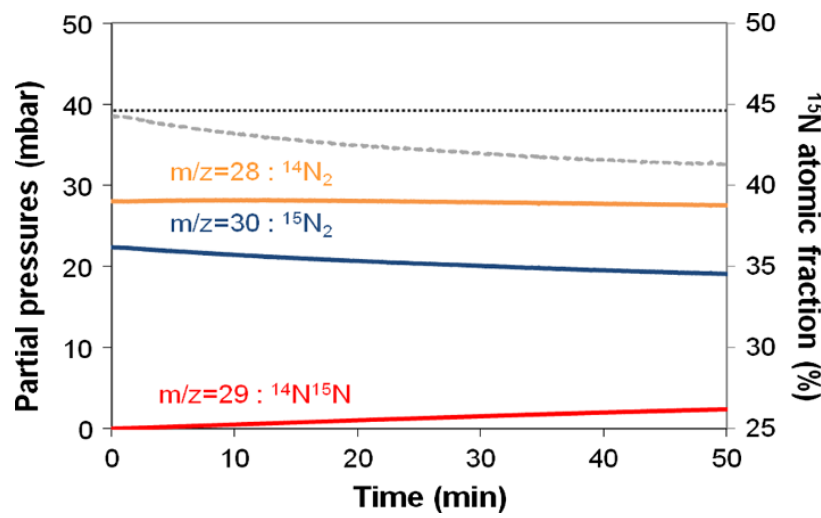

Fig. 2 Evolution of the nitrogen isotopomer partial pressures and the gas-phase ${ }^{15} \mathrm{~N}$ atomic fraction during homomolecular isotopic nitrogen exchange at $450{ }^{\circ} \mathrm{C}$ over $\mathrm{Co}_{3} \mathrm{Mo}_{3} \mathrm{~N}$. Reproduced with permission from [43]. Copyright (2013) American Chemical Society

in the context of the development of the $\mathrm{Co}_{3} \mathrm{Mo}_{3} \mathrm{~N}$ catalytic system at a very much later stage and illustrative of the wide ranging nature of the early work conducted at BASF.

Whilst it was stated that the lattice $\mathrm{N}$ of the $\mathrm{Co}_{3} \mathrm{Mo}_{3} \mathrm{~N}$ catalyst did not participate in the $\mathrm{NH}_{3}$ synthesis reaction, a nitrogen isotopic exchange reaction undertaken by Hunter et al. has shown it to be exchangeable [43]. Figure 2 presents the homomolecular isotopic exchange profile in which a mixture of ${ }^{14} \mathrm{~N}_{2}$ and ${ }^{15} \mathrm{~N}_{2}$ is scrambled over $\mathrm{Co}_{3} \mathrm{Mo}_{3} \mathrm{~N}$ at $450{ }^{\circ} \mathrm{C}$. Most pertinent is the observation that the atomic fraction of ${ }^{15} \mathrm{~N}$ in the gas phase decreases over the course of the reaction which is a clear indication of the operation of the heterolytic exchange pathway in which exchange of gas-phase species with the lattice $\mathrm{N}$ (which is, of course, predominantly ${ }^{14} \mathrm{~N}$ reflecting the natural distribution of nitrogen isotopes) occurs and that the dissociative activation of $\mathrm{N}_{2}$ does not occur. Isotope exchange studies of the materials with ${ }^{15} \mathrm{~N}_{2(\mathrm{~g})}$ only were undertaken at higher reaction temperature and the results and the reaction and pre-treatment conditions are presented in Table 2. From this data, a clear influence of the nature of pre-treatment upon the exchangeability of lattice nitrogen is observedin these studies, the influence of adsorbed $\mathrm{N}$ species was discounted and it was found that ca. $25 \%$ of lattice $\mathrm{N}$ species could be exchanged at $600{ }^{\circ} \mathrm{C}$ following $\mathrm{N}_{2}$ pretreatment at $700{ }^{\circ} \mathrm{C}$ as compared to $6 \%$ for the corresponding pre-treatment in Ar. Whilst these reaction temperatures are significantly above that for ammonia synthesis, the presence of $\mathrm{H}_{2}$ in that case could accentuate the lattice $\mathrm{N}$ reactivity. These results were taken to demonstrate the possibility that the lattice nitrogen may indeed be reactive under reaction conditions and hence that a Mars-van Krevelen type mechanism, in which $\mathrm{NH}_{3}$ formation occurs by direct hydrogenation of lattice species which are then replenished from gas-phase $\mathrm{N}_{2}$, could be
Table 2 Nitrogen isotopic exchange activity of $\mathrm{Co}_{3} \mathrm{Mo}_{3} \mathrm{~N}$ as a function of pre-treatment (adapted from [43])

\begin{tabular}{|c|c|c|c|}
\hline Pre-treatment & $\begin{array}{l}\mathrm{H}_{2} / \mathrm{N}_{2}(3 / 1) \\
700{ }^{\circ} \mathrm{C} / \mathrm{Ar} \\
700{ }^{\circ} \mathrm{C} \\
(30 \mathrm{~min})\end{array}$ & $\begin{array}{l}\mathrm{H}_{2} / \mathrm{N}_{2}(3 / 1) \\
700{ }^{\circ} \mathrm{C} / \mathrm{N}_{2} \\
700{ }^{\circ} \mathrm{C} \\
(30 \mathrm{~min})\end{array}$ & $\begin{array}{l}\mathrm{H}_{2} / \mathrm{N}_{2}(3 / 1) 700{ }^{\circ} \mathrm{C} / \\
\mathrm{Ar} 700{ }^{\circ} \mathrm{C}(30 \mathrm{~min}) / \\
\mathrm{N}_{2} 700{ }^{\circ} \mathrm{C}(30 \mathrm{~min})\end{array}$ \\
\hline $\begin{array}{l}\text { Temperature } \\
\text { of } \\
\text { exchange } \\
\left({ }^{\circ} \mathrm{C}\right)\end{array}$ & 600 & 600 & 600 \\
\hline $\begin{array}{l}{ }^{15} \mathrm{~N}_{2} \text { pressure } \\
\text { introduced } \\
\text { (mbar) }\end{array}$ & 55.6 & 55.1 & 55.0 \\
\hline $\begin{array}{l}\text { Total } \\
\text { pressure at } \\
40 \mathrm{~min}\end{array}$ & 51.4 & 48.5 & 52.3 \\
\hline $\begin{array}{l}{ }^{15} \mathrm{~N}_{\text {exchanged }} / \\
\mathrm{N}_{\text {total } 331} \text { at } \\
40 \mathrm{~min}\end{array}$ & 6 & 28 & 25 \\
\hline
\end{tabular}

operative and the significant effects of pre-treatment upon the extent of exchange demonstrate the sensitivity of the system, possibly involving surface restructuring effects.

\section{Potential of nitrides as nitrogen transfer reagents}

The possible existence of Mars-van Krevelen type reaction mechanisms in both the binary and ternary nitride systems raises the interesting possibility of the development of nitrides as reagents for novel nitrogen transfer pathways. The prospect of such a "mechanism" leads to the idea of a "process".

The mechanism implies two concurrent general stages to ammonia synthesis:

(i) the hydrogenation of lattice $\mathrm{N}$ species to yield $\mathrm{NH}_{3}$, and

(ii) the replenishment of lattice $\mathrm{N}$ vacancies from gasphase $\mathrm{N}_{2}$

In terms of a "process" stages (i) and (ii) could be conducted under different conditions (e.g. at different temperatures) leading to potential kinetic and/or thermodynamic advantages. In oxidation catalysis there is a precedent for the distinction between "mechanism" and "process" as illustrated by the example of butane oxidation catalysed by vanadium phosphate. On the basis that this reaction occurred by a Mars-van Krevelen mechanism it has proved possible to separate the butane oxidation and catalyst re-oxidation steps into separate stages $[44,45]$. In this way, the desired partial oxidation product, maleic anhydride, does not come into direct contact with $\mathrm{O}_{2}$ in the presence of the catalyst. 
Applying this general concept, it may prove possible to develop new nitrogen transfer reagents by-passing the use of $\mathrm{NH}_{3}$ as a nitrogen transfer reagent. The potential value of this idea can be illustrated by consideration of the largescale production of aniline via the selective reduction of nitrobenzene. Considering this process from the viewpoint of $\mathrm{N}_{2}$ as the initial source of nitrogen, the process steps can be considered as:

$$
\begin{gathered}
\mathrm{N}_{2}+3 \mathrm{H}_{2} \leftrightarrow 2 \mathrm{NH}_{3} \\
2 \mathrm{NH}_{3}+4 \mathrm{O}_{2} \rightarrow 2 \mathrm{HNO}_{3}+2 \mathrm{H}_{2} \mathrm{O} \\
\mathrm{HNO}_{3}+2 \mathrm{H}_{2} \mathrm{SO}_{4} \rightarrow \mathrm{NO}_{2}^{+}+\mathrm{H}_{3} \mathrm{O}^{+}+2 \mathrm{HSO}_{4}^{-} \\
\mathrm{C}_{6} \mathrm{H}_{6}+\mathrm{NO}_{2}^{+} \rightarrow \mathrm{C}_{6} \mathrm{H}_{5} \mathrm{NO}_{2}+\mathrm{H}^{+} \\
\mathrm{C}_{6} \mathrm{H}_{5} \mathrm{NO}_{2}^{+}+3 \mathrm{H}_{2} \rightarrow \mathrm{C}_{6} \mathrm{H}_{5} \mathrm{NH}_{2}+2 \mathrm{H}_{2} \mathrm{O}
\end{gathered}
$$

As detailed above, the production of ammonia by Haber-Bosch Process is extremely energy intensive. Having applied this energy to form intermediate ammonia, the second equation (a simplified representation of the Ostwald Process) involves oxidation of some of the hydrogen atoms bonded to each ammonia molecule added in the previous process step. Taken together, these initial two stages represent an indirect way of oxidising hydrogen to yield water! The nitric acid product is then used to form the nitronium cation in corrosive mixture of concentrated acids. Having obtained the nitronium cation benzene is nitrated and the nitrobenzene product selectively reduced to yield aniline-in another stage indirectly involving the reaction between oxygen and hydrogen to yield water!

It might be imagined that the direct amination of benzene:

$\mathrm{C}_{6} \mathrm{H}_{6}+\mathrm{NH}_{3} \leftrightarrow \mathrm{C}_{6} \mathrm{H}_{5} \mathrm{NH}_{2}+\mathrm{H}_{2}$

is a potential alternative route, but it is thermodynamically limited and approaches to overcome this limitation by use of a cataloreactant [46] or coupled hydrogen consuming reactions [47] have proved unsuccessful.

If the lattice nitrogen of a nitride could be used in an alternative aniline forming two-stage process such as:

$\mathrm{C}_{6} \mathrm{H}_{6}+\mathrm{MN}+0.5 \mathrm{H}_{2} \rightarrow \mathrm{C}_{6} \mathrm{H}_{5} \mathrm{NH}_{2}+\mathrm{M}$

and

$\mathrm{M}+$ "N" $\rightarrow \mathrm{MN}$

(where MN represents a metal nitride, $\mathrm{M}$ the corresponding metal and " $\mathrm{N}$ " a nitridation agent such as $\mathrm{NH}_{3}$ or, ideally, $\mathrm{N}_{2}$ ) although a formidable challenge, the potential interest in the development of such a route is readily apparent. Indeed the nitrogen transfer and renitridation stages could be conducted under different reaction conditions. However, non-selective reduction could be a major potential issue. Aniline production is just one of a number of major "nitrogen incorporation"

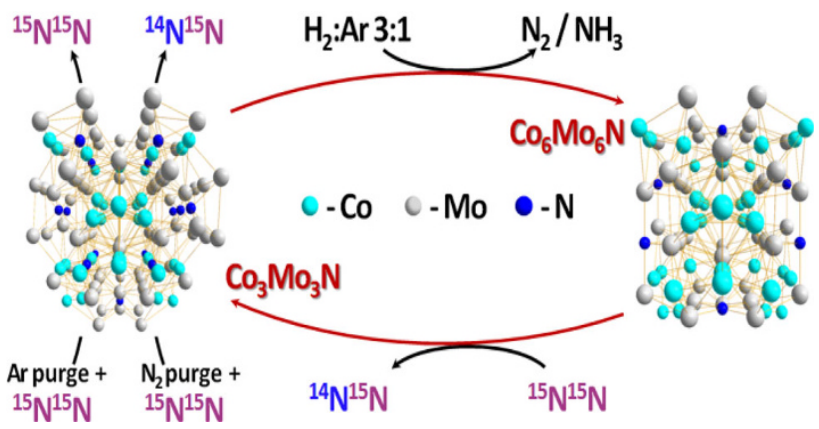

Fig. 3 Schematic of the phase transformations and isotopic exchange pathways over the $\mathrm{Co}_{3} \mathrm{Mo}_{3} \mathrm{~N}-\mathrm{Co}_{6} \mathrm{Mo}_{6} \mathrm{~N}$ system. Reproduced with permission from [43]. Copyright (2013) American Chemical Society

processes for which a similar potential approach may be imagined.

Whilst not widespread, reports of the reactivity of lattice $\mathrm{N}$ are not without precedent, some of which were already mentioned in the section relating to binary nitride catalysts applied to ammonia synthesis. In 1948, Goodeve and Jack [48] published an investigation relating to the denitridation of iron nitride. In this study, hydrogen was shown to enhance the loss of lattice nitrogen leading to its complete conversion to ammonia in the $250-450{ }^{\circ} \mathrm{C}$ range. Interestingly, when $\mathrm{CO}$ was used, $25 \%$ of the nitrogen lost formed cyanogen with isomorphous substitution of lattice $\mathrm{N}$ by $\mathrm{C}$. Lattice nitrogen reactivity has also been implicated in $\mathrm{NH}_{3}$ decomposition over zirconium oxynitride [49] and the ammoxidation of propane over VAlON [50].

With the Mars-van Krevelen process concept in mind, the reactivity of a number of metal nitrides towards $\mathrm{H}_{2}$ has been investigated $[14,38,51,52] . \mathrm{Co}_{3} \mathrm{Mo}_{3} \mathrm{~N}$ proved a particularly interesting case in this regard-at $700{ }^{\circ} \mathrm{C}$ the previously unprecedented $\mathrm{Co}_{6} \mathrm{Mo}_{6} \mathrm{~N}$ phase was formed through loss of $50 \%$ of the lattice nitrogen [51, 52]. Despite the fact that the majority of $\mathrm{N}$ eliminated was in the form of $\mathrm{N}_{2}$, with $\mathrm{NH}_{3}$ being a minor co-product, $\mathrm{H}_{2}$ was necessary to drive the process. In $\mathrm{Co}_{3} \mathrm{Mo}_{3} \mathrm{~N}$ all the lattice nitrogen is crystallographically equivalent and it might be imagined that it would be totally lost upon reaction with $\mathrm{H}_{2}$. However, the residual $50 \%$ relocates to a different crystallographic site (migration from the $16 \mathrm{c}$ to the $8 \mathrm{a}$ Wyckoff site) as confirmed by powder neutron diffraction [52]. Restoration of the $\mathrm{Co}_{3} \mathrm{Mo}_{3} \mathrm{~N}$ phase, which would be a necessary step for its application as a nitrogen transfer reagent, was found to be relatively facile when using a $\mathrm{N}_{2} /$ $\mathrm{H}_{2}$ mix and achievable at higher temperature when using $\mathrm{N}_{2}$ alone [53]. It was demonstrated that the $\mathrm{Co}_{3} \mathrm{Mo}_{3} \mathrm{~N} /$ $\mathrm{Co}_{6} \mathrm{Mo}_{6} \mathrm{~N}$ system can be cycled back and forth. It has tentatively been postulated that the $\mathrm{H}_{2}$ necessary to accomplish the $\mathrm{Co}_{3} \mathrm{Mo}_{3} \mathrm{~N}$ to $\mathrm{Co}_{6} \mathrm{Mo}_{6} \mathrm{~N}$ phase change may 
function by inducing a phase change through reduction of surface stoichiometry-in terms of diffraction analysis, the transformation occurs between the two end members with no intermediate stoichiometries being formed. Isotopic nitrogen exchange over the $\mathrm{Co}_{6} \mathrm{Mo}_{6} \mathrm{~N}$ phase has demonstrated that simultaneously, along with renitridation occurring leading to regeneration of the $\mathrm{Co}_{3} \mathrm{Mo}_{3} \mathrm{~N}$ phase, a degree of exchange occurs with both processes ceasing simultaneously [43]. A schematic of the entire $\mathrm{Co}_{3} \mathrm{Mo}_{3} \mathrm{~N}-$ $\mathrm{Co}_{6} \mathrm{Mo}_{6} \mathrm{~N}$ interconversion and isotopic exchange processes is presented in Fig. 3.

Whilst $\mathrm{Fe}_{3} \mathrm{Mo}_{3} \mathrm{~N}$ is iso-structural with $\mathrm{Co}_{3} \mathrm{Mo}_{3} \mathrm{~N}$, its lattice nitrogen is much less reactive. In terms of $\mathrm{Co}_{3} \mathrm{Mo}_{3} \mathrm{~N}$, the elevated temperature necessary to conduct the loss of $50 \%$ of the lattice nitrogen would lead to carbidation upon contact with hydrocarbon reactants and so it is necessary to either find a means for enhancement of the lattice nitrogen reactivity or to develop different systems of enhanced reactivity. This could involve experimental based studies or, perhaps more excitingly, computational modelling techniques could be applied to design systems with desired lattice nitrogen reactivity. In the $\mathrm{Co}_{3} \mathrm{Mo}_{3} \mathrm{~N}-\mathrm{Co}_{6} \mathrm{Mo}_{6} \mathrm{~N}$ system, it is probable that the renitridation step is enhanced by the maintenance of $50 \%$ of the original nitrogen in the system. In other nitrides, such as $\mathrm{Cu}_{3} \mathrm{~N}$, where $\mathrm{N}$ loss occurs at temperatures of greater potential interest for nitrogen transfer avoiding carbidation, the total loss of nitrogen which is difficult to suppress and the concomitant structural transformation have rendered renitridation extremely difficult [54].

In principle, routes to nitrogen-containing organic products such as amines could be envisaged based upon the application of carbonitrides as reagents involving hydrogenation. This could open up the exciting prospect of indirect routes from $\mathrm{N}_{2}$ and $\mathrm{CH}_{4}$ in three stage procedures involving nitridation, carbidation and reduction separately. In practice, each step could be conducted under different reaction conditions and the sequence of nitridation and carbidation could be reversed. This prospect is a significant challenge but arguably any demonstration of the indirect reaction of methane and nitrogen to yield any organic nitrogen-containing product, and even HCN, would be of major interest. To this end, preliminary investigations of the reduction molybdenum carbonitride systems prepared from single source routes have been undertaken [55]. In these studies, the preferential reactivity of lattice $\mathrm{N}$ over lattice $\mathrm{C}$ has been observed, indicating that it would be necessary to develop materials with more closely matched reactivity of the lattice $\mathrm{N}$ and $\mathrm{C}$ components. Again, computational modelling in which target phases are identified could play a significant role in this regard.
Related alternative strategies for ammonia synthesis

The observations outlined above indicate that it could be possible to apply $\mathrm{Co}_{3} \mathrm{Mo}_{3} \mathrm{~N}$ as a material for the two-stage synthesis of ammonia in which hydrogenation of the lattice nitrogen and its subsequent replenishment from $\mathrm{N}_{2}$ are conducted in separate stages. However, the temperatures involved in this would be high. Also, the mass fraction of $\mathrm{N}$ in the system is very low-an issue compounded when it is considered that only $50 \%$ of the lattice nitrogen is "active" - and only a relatively fraction of it is hydrogenated to yield $\mathrm{NH}_{3}$ with the major proportion being lost in the form of $\mathrm{N}_{2}$.

The design of new, improved systems with greater efficiency of $\mathrm{N}$ utilisation and enhanced reactivity of $\mathrm{N}$ based along these lines represents an exciting opportunity for combined computational modelling and experimental studies. Cyclic operation of ammonia synthesis has been proposed previously in the literature by Amariglio and coworkers as a means of overcoming the inhibition of reaction rate by $\mathrm{H}_{2}$ for $\mathrm{Ru}$ [56] and Os [57] systems. It was suggested that reaction rates of possible commercial interest could be achieved at atmospheric pressure using such an approach in these systems. For example, by applying the cyclic two-step procedure-saturation under pure $\mathrm{N}_{2}$, followed by hydrogenation under pure $\mathrm{H}_{2}$ extrapolation indicated that rates comparable to the industrial performance of iron catalysts could be obtained over $\mathrm{Ru}$ at $300{ }^{\circ} \mathrm{C}$ and atmospheric pressure.

Routes applying solar energy towards nitrogen fixation and the production of ammonia have been described recently by Pfromm and co-workers [58-60]. In these routes, metal nitrides are prepared by various means from $\mathrm{N}_{2}$ and $\mathrm{NH}_{3}$ is generated in a subsequent hydrolysis step. The necessary high temperatures are attained via a solar furnace. The use of a solar furnace as an environmentally friendly means to attain high temperatures for application to nitrogen fixation is an interesting concept. Historically, in the cyanamide process which immediately pre-dated the Haber-Bosch Process, nitrogen fixation was achieved by direct reaction of $\mathrm{N}_{2}$ with calcium dicarbide producing calcium cyanamide $\left(\mathrm{CaCN}_{2}\right)$. Although this process required high temperatures, it was exothermic and selfsustaining once initiated [61]. However, the production of calcium carbide from $\mathrm{CaO}$ and $\mathrm{C}$ necessary for the process did involve the application of very high temperatures. $\mathrm{CaCN}_{2}$ could be directly applied as a fertiliser itself or hydrolysed to liberate ammonia.

\section{Conclusion}

In this overview, selected examples of the applications of metal nitrides as catalysts for the synthesis of ammonia have 
been described. The potential of this class of material for the development of novel nitrogen transfer reagents has also been outlined. It can be anticipated that advances in nitride synthesis coupled with the application of more complex materials, such as quaternary systems, may result in exciting developments in these areas. It is clear that nitride materials represent an interesting opportunity. They are of increasing interest in other areas of heterogeneous catalysis.

Open Access This article is distributed under the terms of the Creative Commons Attribution License which permits any use, distribution, and reproduction in any medium, provided the original author(s) and the source are credited.

\section{References}

1. Smil V (2002) Nitrogen and food production: proteins for human diets. AMBIO J Hum Env 31:126-131

2. Tanabe Y, Nishibayashi Y (2012) Developing more sustainable processes for ammonia synthesis. Coord Chem Rev 257:2551-2564

3. Bielawa H, Hinrichsen O, Birkner A, Muhler M (2001) The ammonia synthesis catalyst of the next generation: barium promoted oxide supported ruthenium. Angew Chemie Int Edn 40:1061

4. Jacobsen CJH (2001) A novel support for ruthenium-based ammonia synthesis catalysts. J Catal 200:1-3

5. Urabe K, Aika K, Ozaki A (1976) Activation of nitrogen by alkali metal promoted transition metal. 6. Hydrogen effect on isotopic equilibration of nitrogen and rate-determining step of ammoniasynthesis on potassium promoted ruthenium catalysts. J Catal 42:197-204

6. Rao KSR, Masthan SK, Prasad PSS, Rao PK (1991) Effect of barium addition on the ammonia synthesis activity of a cesium promoted ruthenium catalyst supported on carbon covered alumina (CAA). Appl Catal 73:L1-L5

7. Honkala K, Hellman A, Remediakis IN, Logadottir A, Carlosson A, Dahl S, Christensen CH, Norskov JK (2005) Ammonia synthesis from first principles calculations. Science 307:555-558

8. Rhodes AK (1996) New ammonia process, catalyst proven in Canadian plant. Oil Gas J 94(47):37-41

9. Liu H (2012) Ammonia synthesis catalysts-innovation and practice. World Scientific Press. ISBN: 978-981-4355-77-3

10. Mittasch A (1950) Early studies of multicomponent catalysts. In: Frankenburg WG, Rideal EK, Komorewsky VI (eds) Advances in catalysis, vol II. Academic Press, New York, pp 81-104

11. Schlogl R (2003) Catalytic synthesis of ammonia-a "never ending story?" Angew Chemie Int Edn 42:2004-2008

12. Volpe L, Boudart M (1986) Ammonia synthesis on molybdenum nitride. J Phys Chem 90:4874-4877

13. Kojima R, Aika K (2001) Molybdenum nitride and carbide catalysts for ammonia synthesis. Appl Catal A Gen 219:141-147

14. Mckay D, Hargreaves JSJ, Rico JL, Rivera JL, Sun XL (2008) The influence of phase and morphology of molybdenum nitrides on ammonia synthesis activity and reduction characteristics. J Solid State Chem 161:325-333

15. Segal N, Sebba F (1967) Ammonia synthesis catalyzed by uranium nitride. 1. Reaction mechanism. J Catal 8:105-112

16. Segal N, Sebba F (1967) Ammonia synthesis catalyzed by uranium nitride. 2. Transient behaviour. J Catal 8:113-119

17. King DA, Sebba F (1965) Catalytic synthesis of ammonia over vanadium nitride containing oxygen. 1. Reaction mechanism. J Catal 4:253-259
18. King DA, Sebba F (1965) Catalytic synthesis of ammonia over vanadium nitride containing oxygen. 2 . Order-disorder transition revealed by catalytic behavior. J Catal 4:430-439

19. Kojima R, Aika K (2001) Rhenium containing binary catalysts for ammonia synthesis. Appl Catal A Gen 209:317-325

20. Kojima R, Enomoto H, Muhler M, Aika K (2003) Cesium promoted rhenium catalysts supported on alumina for ammonia synthesis. Appl Catal A Gen 245:311-322

21. Panov GI, Kharitonov AS (1985) Catalytic properties of nitrides in ammonia synthesis. React Kinet Catal Lett 29:267-274

22. Volpe L, Boudart M (1985) Compounds of molybdenum and tungsten with high surface area. 1. Nitrides. J Solid State Chem 59:332-347

23. Gong SW, Chen HK, Li W, Li BQ (2005) Synthesis of beta$\mathrm{Mo}_{2} \mathrm{~N}_{0.78}$ hydrodesulfurization catalyst in mixtures of nitrogen and hydrogen. Appl Catal A Gen 279:257-261

24. Ganin AY, Kienle L, Vajenine GV (2006) Synthesis and characterisation of hexagonal molybdenum nitrides. J Solid State Chem 179:2339-2348

25. Aika KI, Ozaki A (1969) Mechanism and isotope effect in ammonia synthesis over molybdenum nitride. J Catal 14:311-321

26. Logan SR, Moss RL, Kemball KC (1958) The catalytic decomposition of ammonia over evaporated iron films. Trans Faraday Soc 54:922-930

27. Hillis MR, Kemball C, Roberts MW (1966) Synthesis of ammonia and related processes on reduced molybdenum dioxide. Trans Faraday Soc 62:3570-3585

28. Doornkamp C, Ponec V (2000) The universal character of the Mars and van Krevelen mechanism. J Mol Chem A Chem 162:19-32

29. Kojima R, Aika K (2001) Cobalt molybdenum bimetallic nitride catalysts for ammonia synthesis-Part 1 . Preparation and characterization. Appl Catal A Gen 215:149-160

30. Kojima R, Aika K (2001) Cobalt molybdenum bimetallic nitride catalysts for ammonia synthesis-Part 2. Kinetic study. Appl Catal A Gen 218:121-128

31. Kojima R, Aika K (2001) Cobalt molybdenum bimetallic catalysts for ammonia synthesis-Part 3. Reactant gas treatment. Appl Catal A Gen 219:157-170

32. Jacobsen CJH, Dahl S, Clausen BS, Bahn S, Logadottir A, Norskov JK (2001) Catalyst design by interpolation in the periodic table: bimetallic ammonia synthesis catalysts. J Am Chem Soc 123:8404-8405

33. Jacobsen CJH (2000) Novel class of ammonia synthesis catalysts. Chem Commun 12:1057-1058

34. Boisen A, Dahl S, Jacobsen CJH (2002) Promotion of binary nitride catalysts: isothermal $\mathrm{N}_{2}$ adsorption, microkinetic model, and catalytic ammonia synthesis activity. J Catal 208:180-186

35. Kojima R, Aika K (2000) Cobalt molybdenum bimetallic catalysts for ammonia synthesis. Chem Lett $514-515$

36. Wise RS, Markel EJ (1994) Catalytic $\mathrm{NH}_{3}$ decomposition by topotactic molybdenum oxides and nitrides-effect on temperature programmed gamma- $\mathrm{Mo}_{2} \mathrm{~N}$ synthesis. J Catal 145:335-343

37. Wise RS, Markel EJ (1994) Synthesis of high surface area molybdenum nitride in mixtures of nitrogen and hydrogen. J Catal 145:344-355

38. Hargreaves JSJ, Mckay D (2009) A comparison of the reactivity of lattice nitrogen in $\mathrm{Co}_{3} \mathrm{Mo}_{3} \mathrm{~N}$ and $\mathrm{Ni}_{2} \mathrm{Mo}_{3} \mathrm{~N}$ catalysts. $\mathrm{J}$ Mol Catal A Chem 305:125-129

39. Dahl S, Logadottir A, Jacobsen CJH, Norskov J (2001) Electronic factors in catalysis: the volcano curve and the effect of promotion in catalytic ammonia synthesis. Appl Catal A Gen 222:19-29

40. Attard GA, King DA (1990) Co-adsorption of nitrogen with $\mathrm{Cu}$, $\mathrm{Ag}$ and $\mathrm{Au}$ on $\mathrm{W}(100)$ - the role of metal adatoms in controlling surface reactivity. J Chem Soc Faraday Trans 86:2735-2741 
41. Alexander A-M, Hargreaves JSJ, Mitchell C (2013) The denitridation of nitrides of iron, cobalt and rhenium under hydrogen. Top Catal 56:1963-1969

42. Iida H, Sakamoto K, Takeuchi M, Igarashi A (2013) FischerTropsch synthesis over $\mathrm{Co} / \mathrm{SiO}_{2}$ and $\mathrm{Co}-\mathrm{M}(\mathrm{M}: \mathrm{Ru}, \mathrm{Re}) / \mathrm{SiO}_{2}$ catalysts prepared by a high temperature supercritical drying method. Appl Catal A Gen 466:256-263

43. Hunter SM, Gregory DH, Hargreaves JSJ, Richard M, Duprez D, Bion N (2013) A study of ${ }^{15} \mathrm{~N} /{ }^{14} \mathrm{~N}$ isotopic exchange over cobalt molybdenum nitrides. ACS Catal 3:1719-1725

44. Contractor RM (1999) Dupont's CBT technology for maleic anhydride. Chem Eng Sci 54:5627-5632

45. Bordes E, Contractor RM (1996) Adaptation of the microscopic properties of redox catalysts to the type of gas-solid reactor. Top Catal 3:365-375

46. Desrosiers P, Guan SH, Hagemeyer A, Lowe DM, Lugmair C, Poojary DM, Turner H, Weinberg $\mathrm{H}$, Zhou XP, Armbrust R, Fengler G, Notheis U (2003) Application of combinatorial catalysis for the direct amination of benzene to aniline. Catal Today 81:319-328

47. Becker J, Holderich WF (1998) Amination of benzene in the presence of ammonia using a Group VIII metal supported on a carrier as catalyst. Catal Lett 54:125-128

48. Goodeve C, Jack KH (1948) Kinetics of nitrogen evolution from an iron-nitrogen interstitial alloy. Disc Faraday Soc 4:82-91

49. Soerijanto H, Rodel C, Wild U, Lerch M, Schomaker R, Schlogly R, Ressler T (2007) The impact of nitrogen mobility of zirconium oxynitride catalysts for ammonia decomposition. J Catal 250:19-24

50. Olea M, Florea M, Sack I, Silvy PR, Gaigneaux EM, Marin GB, Grange P (2005) Evidence for the participation of lattice nitrogen from vanadium aluminium oxynitrides in propane ammoxidation. J Catal 232:152-160

51. Mckay D, Gregory DH, Hargreaves JSJ, Hunter SM, Sun XL (2007) Towards nitrogen transfer catalysis: reactive lattice nitrogen in cobalt molybdenum nitride. Chem Commun 29:3051-3053

52. Hunter SM, Mckay D, Smith RI, Hargreaves JSJ, Gregory DH (2010) Topotactic nitrogen transfer: structural transformation in cobalt molybdenum nitrides. Chem Mater 22:2898-2907

53. Gregory DH, Hargreaves JSJ, Hunter SM (2011) On the regeneration of $\mathrm{Co}_{3} \mathrm{Mo}_{3} \mathrm{~N}$ from $\mathrm{Co}_{6} \mathrm{Mo}_{6} \mathrm{~N}$ and $\mathrm{N}_{2}$. Catal Lett 141:22-26

54. Alexander A-M, Hargreaves JSJ, Mitchell C (2012) The reduction of various nitrides under hydrogen: $\mathrm{Ni}_{3} \mathrm{~N}, \mathrm{Cu}_{3} \mathrm{~N}, \mathrm{Zn}_{3} \mathrm{~N}_{2}$ and $\mathrm{Ta}_{3} \mathrm{~N}_{5}$. Top Catal 55:1046-1053

55. AlShalwi M, Hargreaves JSJ, Liggat JJ, Todd D (2012) The reactivity of lattice nitrogen species in molybdenum (oxy)carbonitrides prepared by single-source routes. Mater Res Bull 47:1251-1256

56. Rambeau G, Amariglio H (1981) Improvement of the catalytic performance of a ruthenium powder in ammonia synthesis by use of a cyclic procedure. Appl Catal 1:291-302

57. Rambeau G, Jorti A, Amariglio H (1982) Improvement of the catalytic performance of an osmium powder in ammonia synthesis by the use of a cyclic procedure. Appl Catal 3:273-282

58. Michalsky R, Pfromm PH (2011) Chromium as reactant for solar thermochemical synthesis of ammonia from steam, nitrogen and biomass at atmospheric pressure. Sol Energy 85:2642-2654

59. Michalksy R, Parman BJ, Amanor-Boadu V, Pfromm PH (2012) Solar thermochemical production of ammonia from water, air and sunlight: thermodynamic and economic analyses. Energy 42:251-260

60. Michalsky R, Pfromm PH (2012) An ionicity rationale to design solid phase metal nitride reactants for solar ammonia production. J Phys Chem C 116:23243-23251

61. Topham SA (1985) The history of the catalytic synthesis of ammonia. In: Anderson JR, Boudart M (eds) Catalysis science and technology, vol. 7, Chapter 1. Springer, Berlin 